Revue

Revue de l'histoire des religions

del'histoire des religions

$1 \mid 2005$

Varia

\title{
Pierre Riché, Henri-Irénée Marrou, historien engagé
}

Préface par René Rémond, Les Éditions du Cerf, Paris, 2003, 23,5 cm, 418 p. (« Histoire Biographie »), $35 €$.

\section{François Laplanche}

\section{OpenEdition}

\section{Journals}

Édition électronique

URL : http://journals.openedition.org/rhr/2817

DOI : $10.4000 /$ rhr.2817

ISSN : 2105-2573

\section{Éditeur}

Armand Colin

\section{Édition imprimée}

Date de publication : 1 janvier 2005

Pagination : 124-126

ISSN : 0035-1423

Référence électronique

François Laplanche, «Pierre Riché, Henri-Irénée Marrou, historien engagé », Revue de l'histoire des religions [En ligne], 1 | 2005, mis en ligne le 28 janvier 2010, consulté le 22 septembre 2020. URL http://journals.openedition.org/rhr/2817 ; DOI : https://doi.org/10.4000/rhr.2817 
plupart des controverses politico-religieuses de la fin du XVII ${ }^{\mathrm{e}}$ siècle. Avec la présente Bibliographie critique, ouvrage posthume d'Émile Kappler, publié par les soins d'Antony Mc Kenna, nous disposons d'un incontournable instrument de travail qui est aussi un modèle pour l'établissement de toute bibliographie d'un auteur de l'époque classique. En effet, nous trouvons ici beaucoup plus qu'un relevé de tous les imprimés (même anonymes) de Jurieu, avec description précise et localisation des exemplaires (900 bibliothèques consultées !). E. Kappler a rassemblé pour chacune de ces œuvres tous les éléments accessibles de l'histoire du texte, les comptes rendus, commentaires ou réfutations dont elles ont été l'occasion, toutes les traductions. Il a aussi donné un précieux inventaire des ouvrages faussement attribués à Jurieu (avec discussion approfondie des raisons qui conduisent à les écarter du corpus authentique), ainsi qu'une bibliographie détaillée des ouvrages satiriques écrits contre Jurieu, sans compter de très utiles annexes (géographie des localisations, statistiques, relevé des libraires ayant publié les œuvres, avec des dossiers sur chacun d'eux et sur leurs rapports avec Jurieu, etc.), au total 600 pages de renseignements de première main qui constituent désormais l'entrée de tout travail sur Jurieu, sur ses contemporains, sur les débats d'idées européens et sur l'histoire du livre et de la librairie au temps de la crise de la conscience européenne. Devant une telle abondance de renseignements sûrs et de documents, il serait un peu vain et outrecuidant de relever telle référence inexacte, telle pagination erronée (inexactitudes au demeurant fort rares), ou d'ajouter ici ou là la mention d'une lettre ou d'un manuscrit d'un contemporain de Jurieu. On pourrait seulement souhaiter que soit établi un inventaire critique de la correspondance de Jurieu, comme le fit jadis Élisabeth Labrousse pour celle de Bayle ; cependant les lettres connues de Jurieu semblent moins nombreuses que celles de son adversaire, et de toute façon ce serait un tout autre travail que celui d'Émile Kappler dont l'immense érudition est aujourd'hui pour nous de la plus grande utilité.

\section{Jacques LE BRUN, EPHE (Sciences religieuses), Paris}

Pierre RichÉ, Henri-Irénée Marrou, historien engagé, préface par René Rémond, Les Éditions du Cerf, Paris, 2003, 23,5 cm, 418 p. (« Histoire Biographie »), $35 €$.

Voici un quart de siècle que Marrou a quitté les siens, à la fois sa famille, ses amis et ses disciples, après avoir marqué de sa forte personnalité l'étude de l'antiquité chrétienne en France. Son étudiant et ami Pierre Riché, professeur émérite à l'Université de Paris-X Nanterre, lui consacre un volume biographique respectueux et fervent. Après avoir gravi les premières marches de la carrière (ENS, agrégation, École française de Rome, les 
charges d'enseignement pendant la guerre à Montpellier puis à Lyon), Marrou est élu en 1945 à la chaire d'Histoire ancienne du christianisme tenue par Charles Guignebert de 1906 à 1937. En 1973, il obtiendra une affectation au CNRS qui lui permet de préparer sa succession. Pendant une trentaine d'années, Marrou déploie une inlassable activité d'enseignant, de chercheur, de conférencier. Son passage à la Sorbonne instaure une véritable école d'études patristiques. En effet, quoique parfaitement au fait de l'histoire sociale du christianisme antique, Marrou se tourne avec prédilection vers les grands témoins de la pensée chrétienne aux premiers siècles et sa thèse a eu pour objet les relations de saint Augustin avec la culture antique. Soutenue en 1938, elle est plusieurs fois rééditée avec un long texte de mise au point intitulé Retractatio (il date de 1949). Marrou s'interroge en effet sur le concept de décadence, qu'il a utilisé dans la thèse et qu'il juge inadéquat: de nouvelles formes de culture ne peuvent s'imposer qu'à travers des dépérissements et des remaniements, mais fautil parler de «décadence »? Le problème est plus amplement repris dans Décadence romaine ou Antiquité tardive? (posthume, 1977). Une autre publication célèbre de Marrou fut l'Histoire de l'éducation dans l'Antiquité (1948) qui condensait les intérêts de l'historien et du citoyen en une synthèse qui demeura longtemps, sur ce sujet, l'ouvrage de référence. Enfin, par-delà ces réussites remarquables, Marrou réfléchissait sur la science historique en prenant position contre la restriction du travail de l'historien à l'établissement minutieux des faits. Au récit exact, mais sans vie, de l'histoire à la Seignobos, Marrou, dans la lignée herméneutique qui va du romantisme à Dilthey, oppose la connaissance par sympathie avec le sujet traité, qui rend l'historien intelligent. Esquissée dans plusieurs articles, cette théorie de l'histoire s'exprime de façon complète dans De la connaissance historique (1954), ouvrage plusieurs fois réédité.

À côté des travaux de l'historien, Pierre Riché présente aussi les combats de l'homme et du chrétien : l'engagement dans la Résistance et l'assistance apportée aux Juifs, la participation à la fondation du SGEN et au comité de la rédaction d'Esprit, l'opposition à la guerre d'Algérie et à l'emploi de la torture, les prises de position sur la réforme de l'enseignement et sur la question scolaire, les appréciations sur la répression romaine de la «nouvelle théologie» française. À travers ces récits qui présentent une chronique alerte du catholicisme français de 1935 à 1975, la figure de Marrou apparaît comme celle d'un homme libre, jamais partisan, toujours capable de retourner la critique contre son propre camp quand il le juge nécessaire. Trop catholique pour certains laïques, qui voient mal la chaire de Guignebert occupée par un catholique, il est trop laïque pour beaucoup de catholiques, qui comprennent mal les positions du SGEN ou d'Esprit sur le problème scolaire. Malgré ses liens avec Esprit, qui sont de proximité à la fois matérielle et morale (il habite à Châtenay-Malabry près de la famille Mounier et de Paul Ricœur), Marrou s'inquiète dans les années 1955 de l'orientation de certains rédacteurs vers les thèses des chrétiens 
« progressistes » (séduits par la philosophie marxiste et philo-communistes). En dépit de sa participation à l'amitié judéo-chrétienne et de sa position très claire dans l'affaire Finaly, il critique le livre de Jules Isaac Jésus et Israël, qu'il juge peu exact dans sa relation du procès de Jésus. Vers la fin de sa vie, un peu inquiet des événements qui secouent l'Église et l'Université, il prête l'oreille à la plainte de certains groupes désorientés, mais cherche à les éclairer sans s'y inféoder. Sa docilité sans aveuglement ni bassesse par rapport à la hiérarchie catholique a toutefois étonné ses amis d'Esprit. Elle exprime l'esprit d'une génération d'intellectuels catholiques, souvent plus déférents que les clercs, qui connaissent la maison.

Ce portrait de Marrou campe une haute figure d'intellectuel catholique qui appartient à une époque maintenant révolue et qui peut, de ce fait, être objet d'histoire. Les conditions de la vie universitaire et la situation du catholicisme au sein de la société française ont profondément changé. La contribution de Marrou à l'épistémologie de l'histoire, déjà discutée de son temps, en particulier aux Annales, comme le signale Pierre Riché, est elle aussi datée. De plus, l'approche humaniste de Marrou ne se sépare pas de la vision théologique de l'histoire qu'il a acquise dans son incessante fréquentation d'Augustin. Mais, en dépit des déplacements de notre société et de notre culture, les interrogations profondes de Marrou sur l'histoire et sur son propre temps ouvrent des questions toujours vives : quelle éducation face à une scolarisation de masse ? quel rapport du travail de l'historien et de la décision politique ? Faut-il maudire les Américains ? Comment transmettre la foi catholique à notre époque ? Le dialogue entre juifs et chrétiens est-il possible ? etc. Sous-jacentes à la narration de Pierre Riché, ces questions, et d'autres, ne perdent rien de leur vivacité à être abordées sous le regard lucide de Marrou.

François LAPLANCHE, Centre national de la Recherche scientifique.

Claudia Jullien, Dictionnaire de la Bible dans la littérature française. Figures, thèmes, symboles, auteurs. Vuibert, Paris, 2003, 490 pages, $45 €$.

Il s'agit d'un ouvrage de vulgarisation, qui s'appuie, pour ses références bibliques (et certains commentaires), sur la traduction française de la Bible dans la collection de la Pléiade.

La théorie documentaire est exploitée - un peu maladroitement -, p. 167, à propos des noms de « Dieu », et p. 237. L'indication des termes hébreux, grecs ou latins pour les termes français correspondants, ou celle de la forme biblique des noms propres francisés constituant une entrée est en général trop irrégulière, voire inexacte, pour pouvoir être utilisable. Les articles (plus de deux cents) ne correspondent pas à une encyclopédie de poche de la Bible, mais reflètent l'image qui se dégage de celle-ci à 